\title{
Alpha protons as NMR probes in deuterated proteins
}

\author{
Kumar Tekwani Movellan ${ }^{1} \cdot$ Eszter E. Najbauer ${ }^{1} \cdot$ Supriya Pratihar $^{1} \cdot$ Michele Salvi $^{1} \cdot$ Karin Giller $^{1} \cdot$ Stefan Becker $^{1}$ (1) . \\ Loren B. Andreas ${ }^{1}$
}

Received: 10 December 2018 / Accepted: 28 January 2019 / Published online: 14 February 2019

(C) The Author(s) 2019

\begin{abstract}
We describe a new labeling method that allows for full protonation at the backbone Ho position, maintaining protein side chains with a high level of deuteration. We refer to the method as alpha proton exchange by transamination $(\alpha-\mathrm{PET})$ since it relies on transaminase activity demonstrated here using Escherichia coli expression. We show that $\alpha$-PET labeling is particularly useful in improving structural characterization of solid proteins by introduction of an additional proton reporter, while eliminating many strong dipolar couplings. The approach benefits from the high sensitivity associated with $1.3 \mathrm{~mm}$ samples, more abundant information including $\mathrm{H} \alpha$ resonances, and the narrow proton linewidths encountered for highly deuterated proteins. The labeling strategy solves amide proton exchange problems commonly encountered for membrane proteins when using perdeuteration and backexchange protocols, allowing access to alpha and all amide protons including those in exchange-protected regions. The incorporation of $\mathrm{H} \alpha$ protons provides new insights, as the close $\mathrm{H} \alpha-\mathrm{H} \alpha$ and $\mathrm{H} \alpha-\mathrm{H}^{\mathrm{N}}$ contacts present in $\beta$-sheets become accessible, improving the chance to determine the protein structure as compared with $\mathrm{H}^{\mathrm{N}}-\mathrm{H}^{\mathrm{N}}$ contacts alone. Protonation of the $\mathrm{H} \alpha$ position higher than $90 \%$ is achieved for Ile, Leu, Phe, Tyr, Met, Val, Ala, Gln, Asn, Thr, Ser, Glu, Asp even though LAAO is only active at this degree for Ile, Leu, Phe, Tyr, Trp, Met. Additionally, the glycine methylene carbon is labeled preferentially with a single deuteron, allowing stereospecific assignment of glycine alpha protons. In solution, we show that the high deuteration level dramatically reduces $\mathrm{R}_{2}$ relaxation rates, which is beneficial for the study of large proteins and protein dynamics. We demonstrate the method using two model systems, as well as a $32 \mathrm{kDa}$ membrane protein, hVDAC1, showing the applicability of the method to study membrane proteins.
\end{abstract}

Keywords Isotopic labeling $\cdot$ NMR $\cdot$ Membrane proteins $\cdot$ Structural restraints $\cdot$ Transamination $\cdot$ L-Amino acid oxidase

\section{Introduction}

The study of proteins by nuclear magnetic resonance (NMR) has been continuously evolving to improve sensitivity in order to resolve signals in multidimensional spectra, which serve as the basis for studies of structure and dynamics. For large proteins that tumble slowly in solution, as well as for proteins in the solid state, a high level of deuteration with introduction of selective protons is used to improve proton

Electronic supplementary material The online version of this article (https://doi.org/10.1007/s10858-019-00230-y) contains supplementary material, which is available to authorized users.

Loren B. Andreas

land@nmr.mpibpc.mpg.de

1 Department of NMR Based Structural Biology, Max Planck Institute for Biophysical Chemistry, Am Fassberg 11, Göttingen, Germany relaxation, and therefore narrow lines, by elimination of strong proton-proton dipolar couplings.

Proton detected magic-angle spinning (MAS) NMR studies have employed different combinations of spinning frequency and deuteration to optimize sensitivity and resolution (Andreas et al. 2015; Zhang et al. 2015; Wang and Ladizhansky 2014; Brown 2012; Chevelkov et al. 2006; Zhou et al. 2007; Lewandowski et al. 2011; Akbey et al. 2010). Currently, many applications of proton detected MAS NMR are applied at about $60 \mathrm{kHz}$ with $1.3 \mathrm{~mm}$ rotors, a spinning frequency that for fully protonated samples is not enough to average the strong network of ${ }^{1} \mathrm{H}-{ }^{1} \mathrm{H}$ dipolar couplings. This results in proton line broadening and about $200-300 \mathrm{~Hz}$ proton linewidths (Andreas et al. 2015). The advantage of this spinning frequency is that narrow lines are observed at high sensitivity when selected sites are labeled to $100 \%$ incorporation of protons, while others are deuterated. 
In the most straightforward approach, Escherichia coli expression in $\mathrm{D}_{2} \mathrm{O}$ is followed by exchange with $\mathrm{H}_{2} \mathrm{O} / \mathrm{D}_{2} \mathrm{O}$ to produce a protein with a specific protonation level at amides, and perdeuteration at non-exchangeable sites (Chevelkov et al. 2006; Akbey et al. 2010; Lemaster 1990). A protonation level of $100 \%$ at amide positions results in high resolution when using 40-60 kHz MAS in microcrystalline samples, (Lewandowski et al. 2011) enabling structure determination based on backbone resonances (Zhou et al. 2007).

Accessing aliphatic protons is still an area of active development. Sidechain protons can be selectively introduced using metabolic precursors, which has the advantage that a single isotopomer is typically present and deuterium isotope shifts do not result in broadening, even at $100 \%$ protonation of the selected sites. In various ways, methyl groups of I, L, V, T, A can be incorporated (Tugarinov et al. 2003; Isaacson et al. 2007; Velyvis et al. 2012). Exquisite control of labeling can be afforded using a synthetic approach known as SAIL labeling, with the only downside being the high cost, which has typically restricted applications to labeling only selected amino acid types in cell free expression systems (Kainosho et al. 2006). For fully protonated samples, high magnetic fields and very fast MAS $\sim 100 \mathrm{kHz}$ are required to sufficiently narrow proton resonances. At lower spinning frequencies, deuteration is still required, and approaches to resolve aliphatic protons involve using mixtures of $\mathrm{H}_{2} \mathrm{O}$ and $\mathrm{D}_{2} \mathrm{O}$ during protein expression, along with combinations of protonated or deuterated carbon sources such as glycerol or glucose (Lemaster 1990; Asami et al. 2010). While utilizing the residual protons in perdeuterated samples results in exquisite spectra (Agarwal and Reif 2008), the low labeling level severely limits the ability to measure proton-proton distances. At higher proton concentrations, the carbon resonances are broadened due to deuterium isotope shifts (Asami et al. 2012). Although this is a small effect for $\mathrm{H} \alpha$, since only one proton is directly attached, it would still be desirable to limit the protons introduced in the sidechains, since such protons broaden the alpha resonance, and are a magnetization sink during proton-proton transfer.

We therefore sought a strategy that would allow labeling of alpha protons in E. coli at a cost that allows widespread adoption of the approach for structure determination and dynamics investigations. Previously, an approach for $\mathrm{H} \alpha$ labeling was introduced, where the proton was chemically exchanged in a deuterated amino acid mixture, producing a $\mathrm{D} / \mathrm{L}$ mixture of amino acids, the L portion of which can be utilized directly by bacteria (Yamazaki et al. 1997). Although this previous method was successful, the alpha proton incorporation level was a problem for several amino acids, and serine and threonine were lost during the acetylation and deacetylation reaction. D-amino acids may also inhibit bacterial growth at high concentrations (Hishinuma et al. 1969; Bardaweel 2014). It was also noted that during growth on deuterated amino acid media (O'Brien et al. 2018; Fiaux et al. 2004), exchange of amide moieties occurs, but results in only $10-50 \%$ incorporation of alpha protons for hydrophobic residues (Löhr et al. 2003).

We show an alternative approach that results in up to $100 \%$ $\mathrm{H} \alpha$ incorporation by supplying keto acids. The keto acids are converted by $E$. coli transaminases to the respective amino acids, while adding a proton at the alpha position from the water pool. This avoids any problems due to racemic amino acid mixtures, since the correct L-amino acids are generated enzymatically. The major pathways of amino acid synthesis from glucose and glycerol carbon sources are depicted in Fig. 1a for E. coli. Keto acids are often the direct precursor to an amino acid, indicating that provided a source of keto acids, protons can be introduced via transaminase activity (Fig. 1b), a method hereafter referred to as 'alpha proton exchange by transamination' ( $\alpha$-PET). This method, as with any where the growth medium is based on $\mathrm{H}_{2} \mathrm{O}$, results in protonation of the amide position during protein expression, such that both the alpha and amide positions of the protein are protonated.

Some transaminases are amino acid-specific, like the glutamate-pyruvate aminotransferase that transfers the $\mathrm{NH}_{3}$ from glutamate to pyruvate forming alanine and $\alpha$-ketoglutarate (Kim et al. 2010). Others are less specific for their substrate, such as branched-chain-amino-acid transaminase (BCAT) involved in leucine, isoleucine and valine anabolism (Rudman and Meister 1953). E. coli has a high diversity of such transaminase enzymes, resulting in effective labeling for the majority of residue types.

We generated keto acids by L-amino acid oxidase (LAAO) treatment of a commercial growth medium that is primarily comprised of ${ }^{2} \mathrm{H},{ }^{13} \mathrm{C},{ }^{15} \mathrm{~N}$-amino acids. LAAO enzymes are found in many organisms (Hossain et al. 2014), with different specificity for the substrate amino acids (Nuutinen et al. 2012; Sun et al. 2010). We chose as the enzyme source a crude snake venom containing LAAO, which can be applied directly to the commercial growth medium (Fig. 1c). Additional metabolic pathways might also be important, for example, we observed stereospecific labeling of glycine, which can occur through transaminase, but also by conversion of serine and threonine (Fig. 1d).

Here we show successful introduction of alpha protons for 13 amino acids, with a high deuteration level that improves transverse relaxation rates in both solid and liquid samples.

\section{Methods}

\section{L-amino acid oxidase stock}

$10 \mathrm{mg}$ of LAAO powder (crude extract from the snake venom of Cortalus admanteus, Sigma Aldrich) were 
Fig. 1 Amino acid metabolic pathways and the different enzymatic stages of the $\alpha$-PET labeling method. The metabolic pathways of the TCA cycle are shown in a. In $\mathbf{b}$, the transamination reaction is shown, which is the main route for $\mathrm{H} \alpha$ incorporation. In $\mathbf{c}$, the generation of $\alpha$-keto acids from amino acids by the enzyme LAAO is shown. d Shows the main biosynthesis pathways of glycine with the observed stereospecific labeling

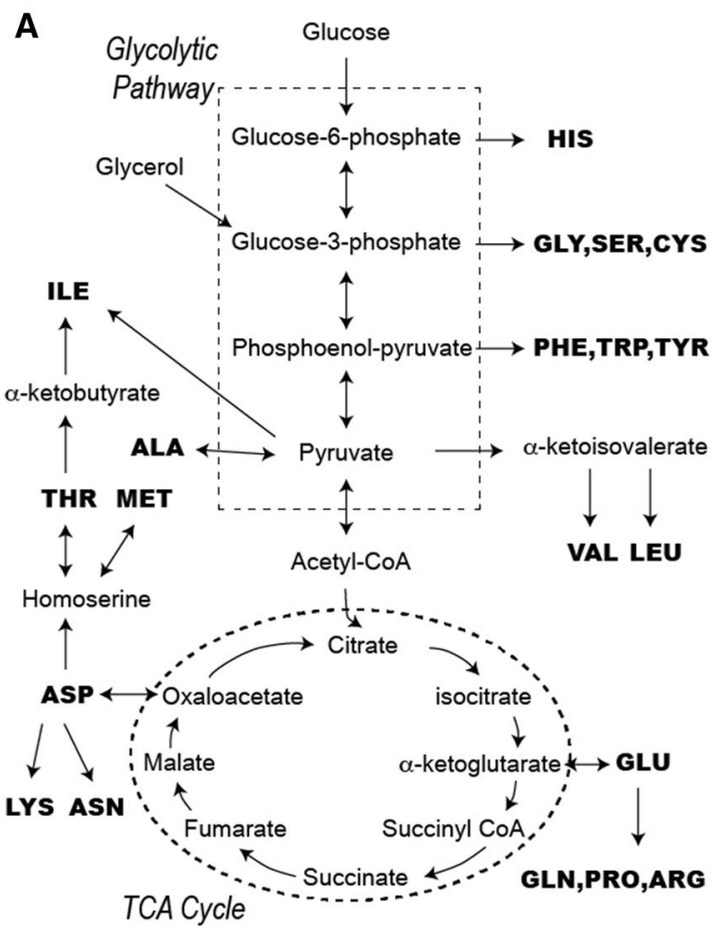

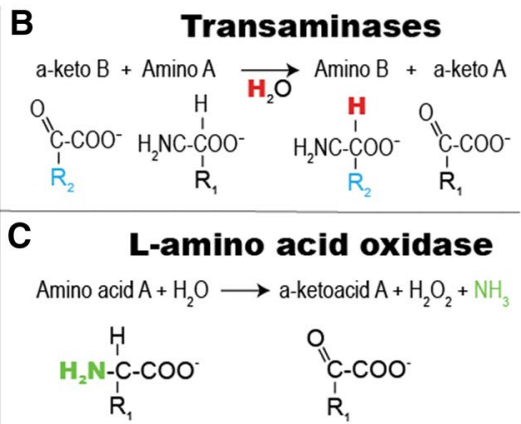

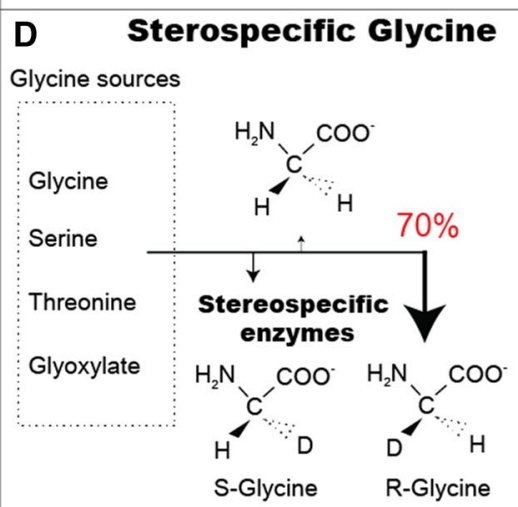

dissolved in $1 \mathrm{ml}$ of $100 \mathrm{mM}$ sodium phosphate, $100 \mathrm{mM}$ $\mathrm{KCl}$ at $\mathrm{pH}$ 7.4. The solution can be kept at $4{ }^{\circ} \mathrm{C}$ for several weeks.

\section{Preparation of keto acid mix}

The amino acid mix (SILEX rich growth media as powder) from Silantes was used as starting material. To obtain keto acids, $1 \mathrm{~g}$ of powder was dissolved in $150 \mathrm{ml}$ of $\mathrm{H}_{2} \mathrm{O}$. To this mixture, $10 \mu$ of bovine liver catalase solution was added at 0 and $12 \mathrm{~h}$ (Sigma, fivefold water dilution from crystalline suspension, 10,000-40,000 units/mg). In total, 3-4 mg of L-amino acid oxidase (LAAO, Sigma) was used per gram powder media, added in equal amounts at 0, 3, 6, 9 and $12 \mathrm{~h}$. The solution was kept shaking at $37^{\circ} \mathrm{C}$ for 1 day, then lyophilized.

\section{Protein expression}

All proteins were expressed in E. coli BL21(DE3). Two NMR model proteins were used, ubiquitin in solution, and microcrystalline chicken alpha-spectrin SH3 (SH3). In addition, the $32 \mathrm{kDa}$ voltage dependent anion channel (VDAC), a beta barrel membrane protein was prepared in lipid bilayers.

For $\alpha$-PET ubiquitin, a change of medium was used prior to expression. E. coli cells were grown in $1 \mathrm{~L}$ of $\mathrm{M} 9$ using $1 \mathrm{~g} / \mathrm{L}$ of ${ }^{15} \mathrm{~N}$ ammonium chloride and $4 \mathrm{~g} / \mathrm{L}$ of ${ }^{13} \mathrm{C}$ glucose until the $\mathrm{OD}_{600 \mathrm{~nm}}$ reached $0.6-0.8$. Then cells were spun down at $7000 \mathrm{~g}$ at $4{ }^{\circ} \mathrm{C}$ for $20 \mathrm{~min}$. The cells were re-suspended in 1L of M9 salts with $4 \mathrm{~g}$ of Silantes media either as received, or treated with LAAO. The cells were adapted to the new media for $30 \mathrm{~min}$ before induction at $\mathrm{OD}_{600 \mathrm{~nm}}=0.8$ with $1 \mathrm{mM}$ of isopropyl $\beta$-D-1thiogalactopyranoside (IPTG). Ubiquitin samples, including a ${ }^{13} \mathrm{C},{ }^{15} \mathrm{~N}$-ubiquitin reference sample were purified as previously described (Lazar et al. 1997).

Using this media exchange protocol, four different samples of ubiquitin were produced, two using ${ }^{2} \mathrm{H}$ Silantes powder treated with LAAO or as received and two others using ${ }^{2} \mathrm{H},{ }^{13} \mathrm{C},{ }^{15} \mathrm{~N}$ Silantes powder again LAAO treated or as received.

Two samples of $\alpha$-PET SH3 were produced, a mediaexchanged sample (as for ubiquitin), and a second $\alpha$-PET $\mathrm{SH} 3$ grown in the presence of glucose. Specifically, the growth was started with a low concentration of $1.25 \mathrm{~g} / \mathrm{L}$ ${ }^{12} \mathrm{C}$-glucose in $800 \mathrm{ml}$ of M9 media. Cells were grown until $\mathrm{OD}_{600 \mathrm{~nm}}$ reached $0.6-0.8$. Then $4 \mathrm{~g} / \mathrm{L}$ of treated Silantes media solubilized in $200 \mathrm{ml}$ of $\mathrm{H}_{2} \mathrm{O}$ were added. The culture was switched to $30{ }^{\circ} \mathrm{C}$ for about $30 \mathrm{~min}$ until $\mathrm{OD}_{600 \mathrm{~nm}}=0.7-0.8$, and protein expression was induced using $1 \mathrm{mM}$ IPTG. A reference sample $\left({ }^{13} \mathrm{C},{ }^{15} \mathrm{~N}-\mathrm{SH} 3\right)$ was expressed and all samples purified as previously described (Pauli et al. 2000). In brief, the protein was purified by anion exchange chromatography (Q-TRAP, GE Healthcare) followed by gel filtration on a Superdex-75 column (GE Healthcare). The purified protein sample was extensively dialyzed against $\mathrm{H}_{2} \mathrm{O}-\mathrm{HCl} \mathrm{pH} 3.5$ for 2 days (exchanging the dialysis solution every $12 \mathrm{~h}$ ). The protein was then 
concentrated (Amicon, $3.5 \mathrm{kDa}$ cut-off) to $20 \mathrm{mg} / \mathrm{ml}$ before lyophilization. The samples were resuspended in $\mathrm{H}_{2} \mathrm{O}-\mathrm{HCl}$ $\mathrm{pH} 3.5$ or $\mathrm{D}_{2} \mathrm{O}-\mathrm{HCl} \mathrm{pH} 3.5$ at $15-20 \mathrm{mg} / \mathrm{ml}$. Microcrystals were obtained using a $\mathrm{pH}$ shift protocol as previously described (Chevelkov et al. 2007).

$\alpha$-PET VDAC was expressed at $37^{\circ} \mathrm{C}$ in dilute glucose media (as for SH3) and purified and reconstituted in 2D crystalline arrays as previously described (Eddy et al. 2012; Dolder et al. 1999). The E73V, C127A, C232S variant of human VDAC was used.

\section{NMR measurements}

Solution NMR data were recorded in a $400 \mathrm{MHz}$ Bruker spectrometer at $298 \mathrm{~K}$. We recorded a set of spectra to characterize the labeling pattern: ${ }^{15} \mathrm{~N}-\mathrm{HSQC},{ }^{13} \mathrm{C}-\mathrm{HSQC}$ in $\mathrm{D}_{2} \mathrm{O},{ }^{1} \mathrm{H}-{ }^{15} \mathrm{~N}$ TOCSY-HSQC, and 1D proton spectra. Quantification of $\mathrm{H} \alpha$ was done from a ${ }^{13} \mathrm{C}-\mathrm{HSQC}$ spectrum at $950 \mathrm{MHz}$ at $310 \mathrm{~K}$. Transverse relaxation rates (R2) were measured at $277 \mathrm{~K}$ using a $600 \mathrm{MHz}$ Bruker spectrometer equipped with a $5 \mathrm{~mm}$ cryoprobe.

The black spectrum of Fig. 6a was recorded at $105 \mathrm{kHz}$ MAS on a $950 \mathrm{MHz}$ Bruker spectrometer using a $0.7 \mathrm{~mm}$ HCND probe. All other solid state NMR data were recorded on an $800 \mathrm{MHz}$ Bruker spectrometer using a $1.3 \mathrm{~mm}$ narrow bore $\mathrm{HCN}$ probe and spinning at $55 \mathrm{kHz}$ MAS. We recorded cross-polarization based $(\mathrm{H}) \mathrm{NH},(\mathrm{H}) \mathrm{CH}$, and $(\mathrm{H}) \mathrm{CANH},(\mathrm{H})$ NCAHA for resonance assignment of VDAC and SH3. We measured contacts in $\mathrm{H}(\mathrm{H}) \mathrm{CH}, \mathrm{H}(\mathrm{H}) \mathrm{NH}$ spectra ( $\mathrm{SH} 3$ ) and (H)C(HH)CH (VDAC) using RFDR for the proton-proton mixing. The spectra were apodized with a squared cosine function (details in Table S6). The data analysis was performed using CcpNMR and Sparky.

\section{Results and discussion}

\section{Characterization of the labeling pattern}

To measure labeling patterns on an amino acid specific basis, we recorded a ${ }^{13} \mathrm{C}$ HSQC spectrum and integrated isolated peaks in the alpha region (Fig. 2). The level of $\mathrm{H} \alpha$ incorporation was determined assuming ideal incorporation of hydrophobic residues, based on complete reaction with LAAO. The uncorrected and $\mathrm{T}_{2}$ corrected determinations are shown in Tables S2 and S3, respectively. A ${ }^{15} \mathrm{~N}$-TOCSY (Fig. 3) was recorded using a medium-range mixing time (75 ms) to assess suppression of sidechain protons. This spectrum cannot be used in a quantitative manner due to the potential for several isotopomers, differential relaxation, and relayed transfer. However, since the beta protons are relatively isolated from these effects, we could show effective suppression for most amino acid types. Figure 2

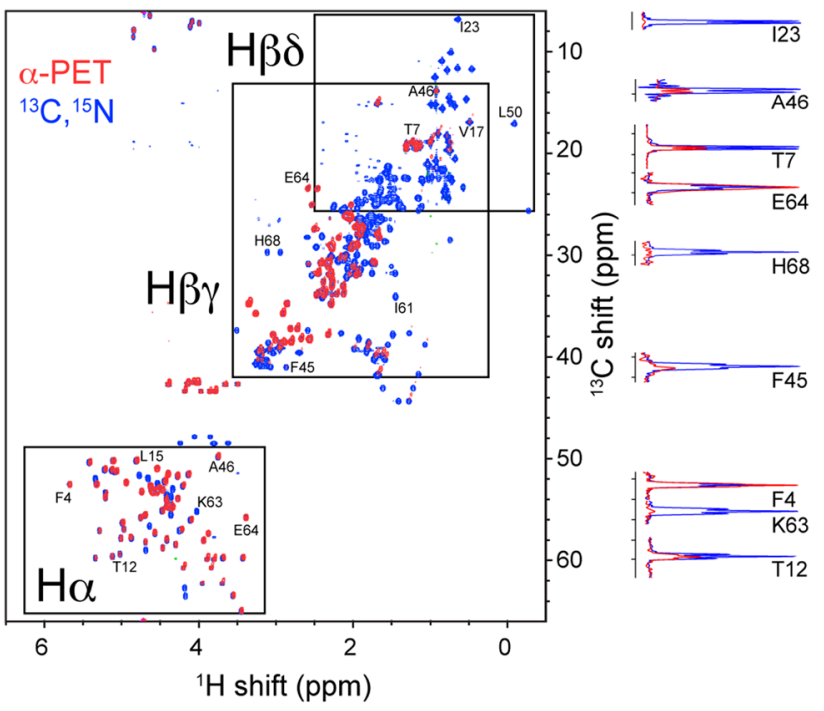

Fig. 2 Effective incorporation of $\mathrm{H} \alpha$ protons in a ubiquitin sample, while suppressing many side-chain signals. The solution ${ }^{13} \mathrm{C}-\mathrm{HSQC}$ of uniformly labelled ubiquitin (blue) is compared with $\alpha$-PET ubiquitin (red). Selected slices show the intensity at backbone and sidechain sites. Intensities are not corrected for differences in $\mathrm{T}_{2}$

shows selected strips for each of the amino acid types of ubiquitin; the ${ }^{1} \mathrm{H}-{ }^{15} \mathrm{~N}$ TOCSY-HSQC of $\alpha$-PET Ubiquitin (red) is compared to the ${ }^{15} \mathrm{~N},{ }^{13} \mathrm{C}$-labeled reference sample (black). The TOCSY was implemented with MLEV-17 mixing (Bax and Davis 1985). The H $\alpha$ proton was detectable for 13 of the 16 (non-proline) amino acid types present in the ubiquitin sequence. Only lysine, arginine and histidine remained deuterated at $\mathrm{H} \alpha$. This can be explained for lysine because Cortalus admanteus LAAO is not able to use it as substrate (Fig S1), and the deuterated amino acids are taken up in E. coli, while endogenous synthesis is suppressed (Zhou et al. 1998). Although LAAO showed some activity for arginine and histidine, these two amino acids are clearly relatively poor substrates of LAAO as reported in previous studies (Arbor 1967) and also herein (Figs. S1 and S4), and therefore it appears that the resulting keto acid could not be utilized by $E$. coli, while the remaining amino acid was effectively incorporated in the protein.

Of the 13 successful amino acid types, tyrosine, phenylalanine, isoleucine, valine, alanine, threonine and aspartic acid residues show only $\mathrm{H} \alpha$ signals in the ${ }^{1} \mathrm{H}-{ }^{15} \mathrm{~N}$ TOCSYHSQC spectrum. The anabolic pathway of these residues ends with an aminotransferase reaction, with the exception of threonine, which explains the labeling. Effective aspartic acid labeling was unexpected since it enters and exits the TCA cycle, but is explained by the very high starting concentration.

The amino acid mix from Silantes (Table S1) is obtained from bacterial proteins by an $\mathrm{HCl}$ proteolysis and consequently glutamine, asparagine, tryptophan, and cystein are 


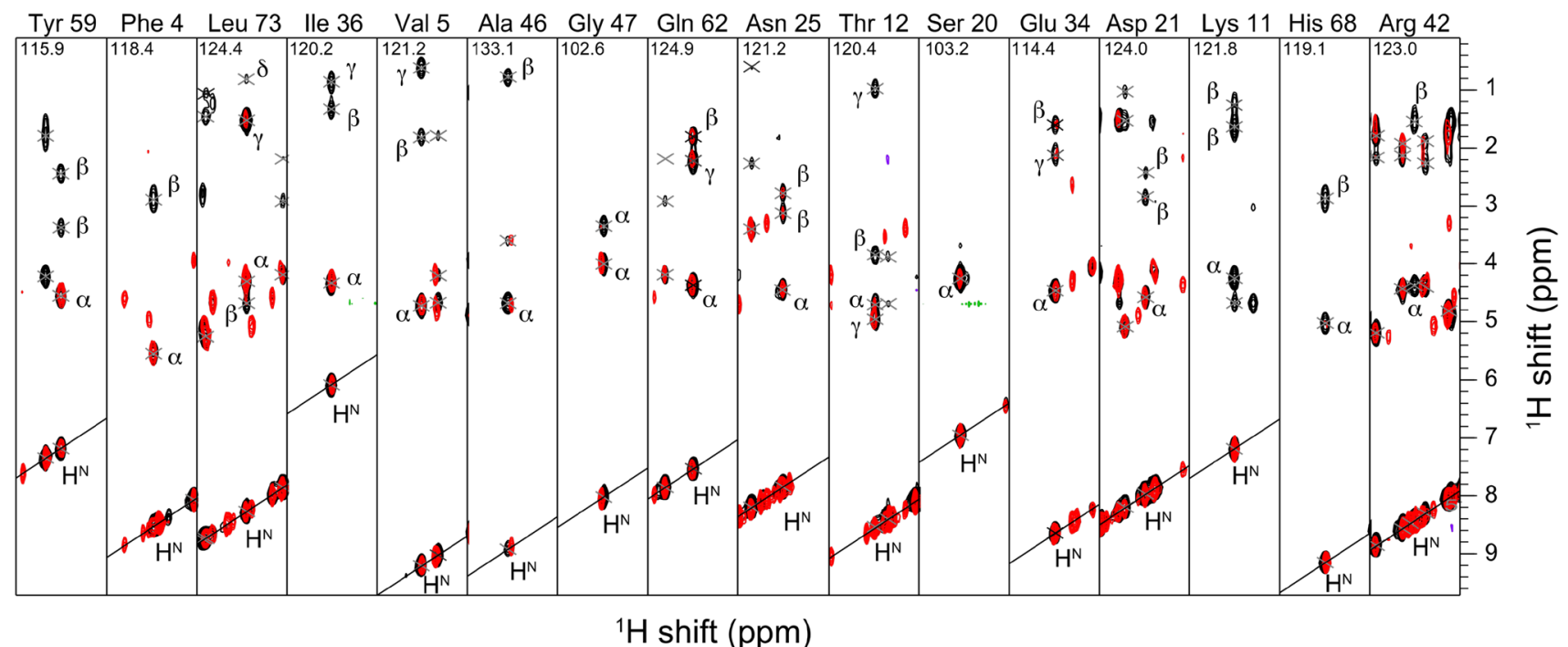

Fig. 3 Residue-specific characterization of labeling from ${ }^{1} \mathrm{H}-{ }^{15} \mathrm{~N}$ TOCSY-HSQC spectra of $1 \mathrm{mM}$ ubiquitin using $75 \mathrm{~ms}$ MLEV-17 mixing. $\alpha$-PET ubiquitin (red) is compared with ${ }^{15} \mathrm{~N},{ }^{13} \mathrm{C}$-ubiquitin (black)

not present in the media. Therefore, glutamine and asparagine require conversion from the respective acids, which explains protonation of beta and gamma protons for these residues (Fig. 1). Glutamic acid efficiently enters and exits the TCA cycle, which may explain the incomplete suppression of beta and gamma protons.

Leucine side-chain protons were not expected, but appear to some extent due to LAAO treatment (Fig. S2). If the LAAO treatment is not performed, this sidechain labeling is not observed (Fig. S7), thus it is the crude snake venom extract that introduces leucine $\mathrm{H} \gamma$ protons. Details of this side reaction were not investigated further, however we did follow the reaction of LAAO to test efficiency in different buffer conditions for a variety of amino acids (Figs. S1-S5).

For most amino acids, the reaction proceeded as expected, and the snake venom LAAO was particularly efficient for hydrophobic amino acids such as phenylalanine and isoleucine (Crotalus and Allen 2013; Arbor 1967). The degree of conversion to keto acids was also tested for all 20 amino acids directly in the Silantes medium. To distinguish the signal from the individual amino acid without significantly changing the composition, we used deuterated Silantes media, and added only $100 \mu \mathrm{M}$ of each protonated amino acid. In this way, we rule out potential issues such as competitive binding to the enzyme and determine the approximate starting concentration of all amino- and keto- acids in the medium (Table 1).

Quantification of the labeling for each residue type is tabulated in Tables S2 and S3 based on intensities extracted from ${ }^{13} \mathrm{C}$-HSQC spectra. The intensities were corrected for the measured proton transverse relaxation rates (Fig. S11) and normalized based on the assumption of complete incorporation of isoleucine, phenylalanine, and leucine residues, which were cleaved completely and are known to effectively incorporate in E. coli (Tugarinov et al. 2003).

We also found that efficient transamination occurs when E. coli is grown primarily on amino acids. Some exchange still occurs at amide positions even without LAAO treatment

Table 1 LAAO activity in deuterated Silantes media, as determined by solution NMR. Each amino acid was added in protonated form at a concentration of $100 \mu \mathrm{M}$ and LAAO was added exactly as described

in the methods section for expression. The remaining alpha signal intensity was used to determine the degree of conversion to keto acid

\begin{tabular}{llcc}
\hline Keto acid conversion $(\%)$ & Residue & Measured Ho incorporation (\%) & Residue* $^{*}$ \\
\hline 90-100 & Ile, Leu, Phe, Tyr, Trp, Met & $90-100$ & $\begin{array}{c}\text { Ile, Leu, Phe, Tyr, Met, Val, } \\
\text { Ala, Gln, Asn, Thr, Ser, Glu, } \\
\text { Asp }\end{array}$ \\
10-50 & & \\
$0-10$ & Val, Arg, His & $10-50$ & Lys, Arg, His \\
& Gly, Pro, Cys, Asn, Gln, Asp, Glu, Ser, Thr, & $0-10$ & \\
\hline
\end{tabular}

* Of 16 amino acids that could be quantified (see SI) 
(Figs. S6, S7), consistent with a previous report showing significant $\mathrm{H} \alpha$ labeling for TCA cycle amino acids, but only $10-50 \% \mathrm{H} \alpha$ labeling for hydrophobic residues (Löhr et al. 2003).

\section{Glycine is labeled stereospecifically}

The H $\alpha$ labeling of glycine attracts particular attention, since one of the two $\mathrm{H} \alpha$ protons is labeled predominantly, resulting in stereospecific glycine labeling (Figs. 2, 4). For glycine 28 , the intensity ratio between the two alpha protons for microcrystalline ${ }^{13} \mathrm{C},{ }^{15} \mathrm{~N} \mathrm{SH} 3$ (Fig. 4, black) is $1-0.93$ while the ratio is $1-0.30$ for $\alpha$-PET SH3 (Fig. 4 , red). This effect was observed for glycine in all the samples tested, based on signal intensity in HSQC and CP-HSQC spectra. We also observed a considerable reduction in line width, by more than a factor of three.

Glycine can be produced from serine by hydroxymethyltransferase, from threonine by L-allo-threonine aldolase, or through serine-glyoxylate or alanine-glyoxylate transaminases. Information in $E$. coli is limited, but analysis of other organisms using tritiated water indicates that the stereo specificity depends on the pathways involved (Yoshimura et al. 1996; Dunathan et al. 1968; Wellner 1970). If serine transhydroxymethylase acts in tritiated water, the resulting glycine will predominantly be the $\mathrm{S}$ configuration, but if liver transaminase acts then $\mathrm{R}$ will be the predominant configuration. Note that in our case, each enzyme will produce the reverse stereoisomer because the starting amino acid is deuterated, and the enzymatic reaction occurs in protonated water. By examination of NOE spectra of ubiquitin we observed a cross peak between the glycine $47 \mathrm{H} \alpha$ and isoleucine $45 \mathrm{H}^{\mathrm{N}}$, which according to the known structure, indicates that glycine was predominantly the $\mathrm{R}$ configuration. This is consistent with the stereospecific labelling approach reported previously using cell free extracts (Loscha and Otting 2013), but results in the opposite labeling, since we expressed in $\mathrm{H}_{2} \mathrm{O}$ rather than $\mathrm{D}_{2} \mathrm{O}$. We can therefore rule out deuterated glycine from the medium as the main source of stereospecific glyine found in the expressed protein.

\section{Resolution and structural data under MAS conditions}

To demonstrate that the $\alpha$-PET labeling scheme results in improved resolution, we prepared a microcrystalline sample of $\alpha$-spectrin SH3 according to established crystallization protocols (Pauli et al. 2000). The $\mathrm{H} \alpha$ line width is significantly reduced for $\alpha$-PET SH3 and the effect is particularly improved for certain residues, by a factor of two and above (Fig. 4). The proton resolution is also superior to labeling with deuterated glucose in otherwise protonated media

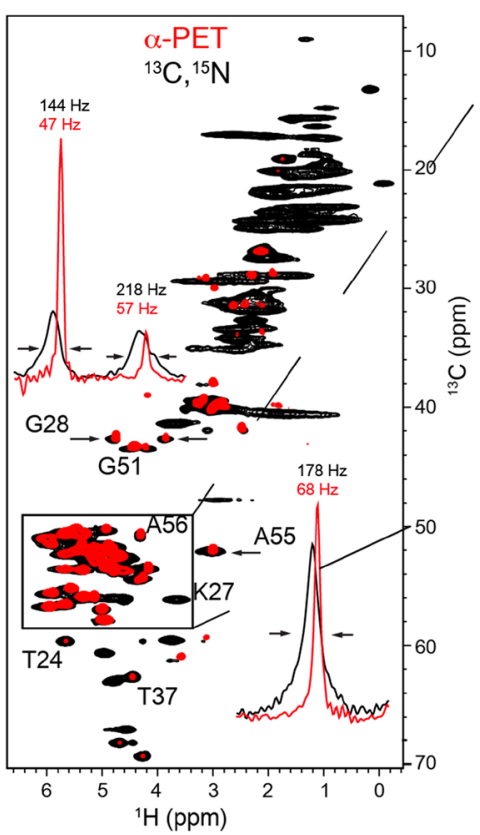

Fig. 4 Cross-polarization based carbon-proton correlation spectra, $\mathrm{hCH}$, of microcrystalline SH3 either uniformly $\alpha$-PET labeled (red) and ${ }^{13} \mathrm{C},{ }^{15} \mathrm{~N}$-labled (black) crystalized from a protonated buffer. Spectra were recorded at a magnetic field of $800 \mathrm{MHz}$ and $30{ }^{\circ} \mathrm{C}$, $55 \mathrm{kHz}$ MAS. 1D slices from the spectrum indicate the improvement in linewidths for G28 (top left) and A55 (bottom right). The glycine peak intensities show stereospecific labeling with preference for $\mathrm{R}$ ( $\alpha 3$ protonated) over $S(\alpha 2)$ configuration. At the bottom right, the backbone and side-chain protons are indicated on the solution NMR structure (pdb: 1aey) for $\alpha$-PET SH3 (red ribbon) and ${ }^{13} \mathrm{C},{ }^{15} \mathrm{~N} \mathrm{SH} 3$ (black ribbon) 
(Medeiros-Silva et al. 2016) (Fig. S8). To characterize the narrowing of the homogeneous part of the lines, the bulk $\mathrm{T}_{2}$ ' relaxation times at $55 \mathrm{kHz}$ was measured for $\mathrm{H} \alpha, \mathrm{C} \alpha$, and CO from 1D (HCAN)H, (HCON)H and (HCA)HA spectra by integrating the full signal. The $\mathrm{H} \alpha ~ \mathrm{~T}_{2}{ }^{\prime}$ of 3-4 ms for $\alpha$-PET SH3 is a dramatic improvement compared to $1 \mathrm{~ms}$ for the fully protonated sample (Fig S9).

The H $\alpha \mathrm{T}_{2}^{\prime}$ of $\alpha$-PET SH3 crystallized in $100 \% \mathrm{D}_{2} \mathrm{O}$ buffer ranged from 7 to $15 \mathrm{~ms}$, an improvement over the amide protonated sample large enough that we can directly observe an increase in resolution in the 1D spectrum (Fig S9). The improvement is further characterized for select residues in Figure $\mathrm{S} 12$. The $\mathrm{H}^{\mathrm{N}}$ signals were almost completely removed in the $\mathrm{D}_{2} \mathrm{O}$ buffer.

Sequential resonance assignment in Fig. 4 were made using a (H)NCAHA spectrum, and are consistent with those previously reported (Xue et al. 2017). SH3 has 62 residues, of which, two are prolines and the N-terminal seven residues and residues 46-48 are flexible and are therefore not observed using cross-polarization based transfer experiments. Thus $50 \mathrm{H} \alpha$ peaks are expected for ${ }^{13} \mathrm{C},{ }^{15} \mathrm{~N} \mathrm{SH} 3$. For $\alpha$-PET SH3 lysine, arginine and histidine are not expected. Thus only $41 \mathrm{H} \alpha$ peaks are expected and indeed 41 peaks were readily identified in (H)NCAHA spectra.

Figure 5 shows a comparison between $\alpha$-PET SH3 in fully protonated buffer (red) and $\alpha$-PET SH3 in fully deuterated buffer (blue) in which long-range structural restraints were measured. To characterize the benefit of the restraints present with $\alpha$-PET labeling, we manually selected peaks in the $\mathrm{H}(\mathrm{H}) \mathrm{CH}$ and $\mathrm{H}(\mathrm{H}) \mathrm{NH}$ spectra, and used automated shift matching $\left(0.05,0.5\right.$ and $0.5 \mathrm{ppm}$ tolerance, in ${ }^{1} \mathrm{H},{ }^{13} \mathrm{C}$ and ${ }^{15} \mathrm{~N}$, respectively) to identify contacts. Of 114 automatically assigned peaks from the 3D H(H)NH of $\alpha$-PET SH3 in protonated buffer, two unambiguous contacts were identified, of which one is a long-range $\mathrm{H}^{\mathrm{N}-} \mathrm{H}^{\mathrm{N}}$ contact. For the 3D $\mathrm{H}(\mathrm{H}) \mathrm{CH}, 132$ peaks were selected, and seven unambiguous contacts were identified, five of which are long-range restraints. However, for the $\mathrm{H}(\mathrm{H}) \mathrm{CH}$ spectrum in deuterated
Fig. 5 Long-range distance information is highlighted in a $3 \mathrm{D} \mathrm{H}(\mathrm{H}) \mathrm{CH}$ spectrum of $\alpha$-PET $\mathrm{SH} 3$ (pdb: 1aey) in $\mathrm{D}_{2} \mathrm{O}$ (blue) and in $\mathrm{H}_{2} \mathrm{O}$ (red). a Shows a contact between $\mathrm{L} 33 \mathrm{H} \alpha$ and V44 H $\alpha$. In b, the contact between $\mathrm{T} 32 \mathrm{H} \alpha$ and $\mathrm{L} 8 \mathrm{H} \alpha$ is readily observed in $\mathrm{D}_{2} \mathrm{O}$ (in blue) while it is much weaker in the presence of additional protons in $\mathrm{H}_{2} \mathrm{O}$ (in red). Recorded in a $800 \mathrm{MHz}$ Bruker spectrometer at $30^{\circ} \mathrm{C}$ and $55 \mathrm{kHz}$ MAS
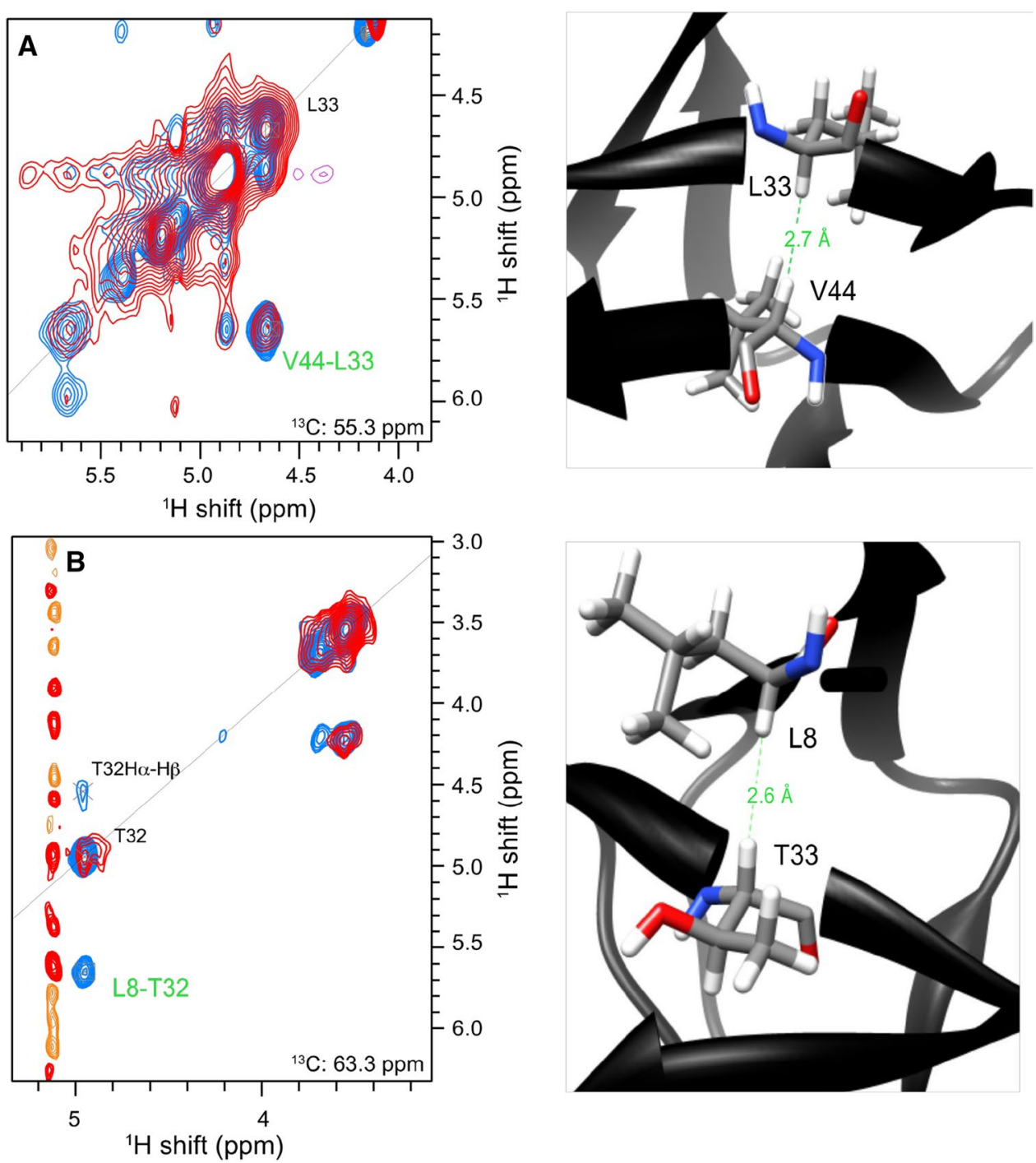
buffer we found 150 contacts, of which eight are unambiguous restraints, seven of which were long range corresponding to either $\mathrm{H}^{\mathrm{N}}-\mathrm{H} \alpha$ or $\mathrm{H} \alpha-\mathrm{H} \alpha$. One of the additional contacts identified in fully deuterated buffer is highlighted in Fig. 5 b. This method clearly improves the number of structural restraints available at $55 \mathrm{kHz}$ MAS, and in particular, the unambiguous restraints, a metric that is crucial for the convergence of commonly used structure calculation methods. A concern with $\mathrm{H} \alpha$ detection is the presence of water and other solvent signals in this spectral region. Therefore good water suppression is needed, but as demonstrated here for samples in both $\mathrm{H}_{2} \mathrm{O}$ and $\mathrm{D}_{2} \mathrm{O}$, control of the water is possible even without gradient methods.

For resonance assignment, the $\alpha$-PET labeling approach benefits from the implementation of new proton detected NMR pulse sequences focused on $\mathrm{H} \alpha$ detection that were recently developed for $>100 \mathrm{kHz}$ MAS (Stanek et al. 2016). So far, proton detected MAS NMR structures were mostly based on $\mathrm{H}^{\mathrm{N}}$ detected experiments or more recently on fully protonated samples that are best investigated using $>100 \mathrm{kHz}$ MAS. (Cala-De Paepe et al. 2017) New possibilities are opened with the $\alpha$-PET approach, allowing effective structural measurements with the inherently more sensitive equipment for $\sim 60 \mathrm{kHz}$ spinning.
The method was also successful for a more challenging system, the human voltage-dependant anion channel (VDAC). The lipid bilayer structure of this protein has been investigated through MAS NMR spectra of VDAC in liposomes (Schneider et al. 2010) and in 2D crystalline arrays (Eddy et al. 2015), and narrow proton resonances were reported for a perdeuterated sample.(Eddy et al. $2015 \mathrm{a}, \mathrm{b}) \mathrm{With} \alpha$-PET labeling, we also observed narrow amide proton linewidths of $150 \mathrm{~Hz}$ in $\mathrm{H}_{2} \mathrm{O}$, while $\sim 100 \mathrm{~Hz}$ lines were observed using $\mathrm{D}_{2} \mathrm{O}$ buffer, which is slightly better than the $\sim 120 \mathrm{~Hz}$ linewidths observed for perdeuterated and $\mathrm{H}^{\mathrm{N}}$ back-exchanged protein. This indicates that the non-exchangeable protons are slightly narrower, and that $\mathrm{H} \alpha$ labeling does not significantly impact the spectral quality. In this $\mathrm{D}_{2} \mathrm{O}$-exchanged buffer, less improvement in $\mathrm{H} \alpha \mathrm{T}_{2}^{\prime}$ (Fig. S9) was observed as compared with the SH3 domain, which is not unexpected, since approximately half the amide protons were protected from exchange (Fig. S9B)

To further characterize the potential spectral resolution, $\alpha$-PET VDAC was measured at $105 \mathrm{kHz}$ MAS at a $950 \mathrm{MHz}$ spectrometer (black in Fig. 6a). Surprisingly, the same line width was obtained at $110 \mathrm{kHz}$ MAS at $950 \mathrm{MHz}(\sim 110 \mathrm{~Hz})$ and at $55 \mathrm{kHz}$ MAS at $800 \mathrm{MHz}(\sim 95 \mathrm{~Hz})$, showing that the inhomogeneous contributions are dominating the linewidth
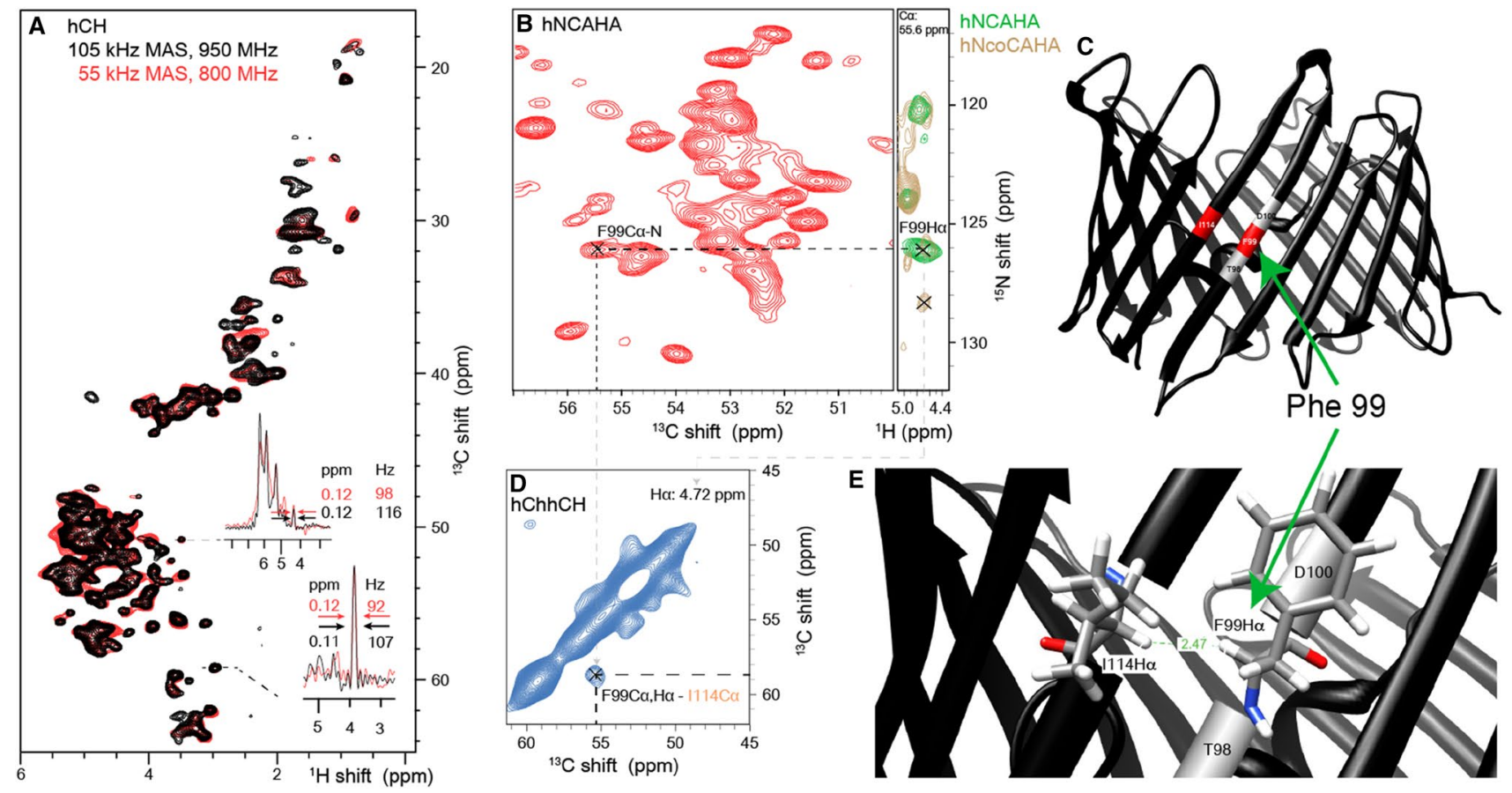

Fig. 6 Identification of a cross beta strand contact (F99-I114 H $\alpha$ ) in the beta barrel membrane protein VDAC in lipid bilayers. a Shows, the comparison of the $(\mathrm{H}) \mathrm{CH}$ spectrum at $105 \mathrm{kHz}$ on a $950 \mathrm{MHz}$ spectrometer (black) and at $55 \mathrm{kHz}$ on an $800 \mathrm{MHz}$ spectrometer (red). b Shows a ${ }^{13} \mathrm{C}-{ }^{15} \mathrm{~N}$ projection of a (H)NCAHA spectrum. F99
$\mathrm{H} \alpha$ is assigned from the strip comparing (H)NCAHA (green) and $(\mathrm{H})$ $\mathrm{N}(\mathrm{CO}) \mathrm{CAHA}$ (brown). In $\mathbf{c}$ and $\mathbf{e}$, the contact is shown on the X-ray structure of mouse VDAC (pdb: 2jk4). d Shows the F99-I114 crosspeak in the carbon-carbon $2 \mathrm{D}$ plane of the $(\mathrm{H}) \mathrm{C}(\mathrm{HH}) \mathrm{CH}$ spectrum at the proton frequency of F99, $4.72 \mathrm{ppm}$ 
Fig. 7 Selected residues showing the reduction in proton $(\mathrm{H} \alpha)$ $\mathrm{R}_{2}$ relaxation rates with $\alpha$-PET labeling (red) as compared with full protonation (black). The correlation plot (right) shows a reduction for all residues. The data is from ubiquitin samples exchanged in $100 \% \mathrm{D}_{2} \mathrm{O}$ at $277 \mathrm{~K}$ and measured at a $600 \mathrm{MHz}$ spectrometer
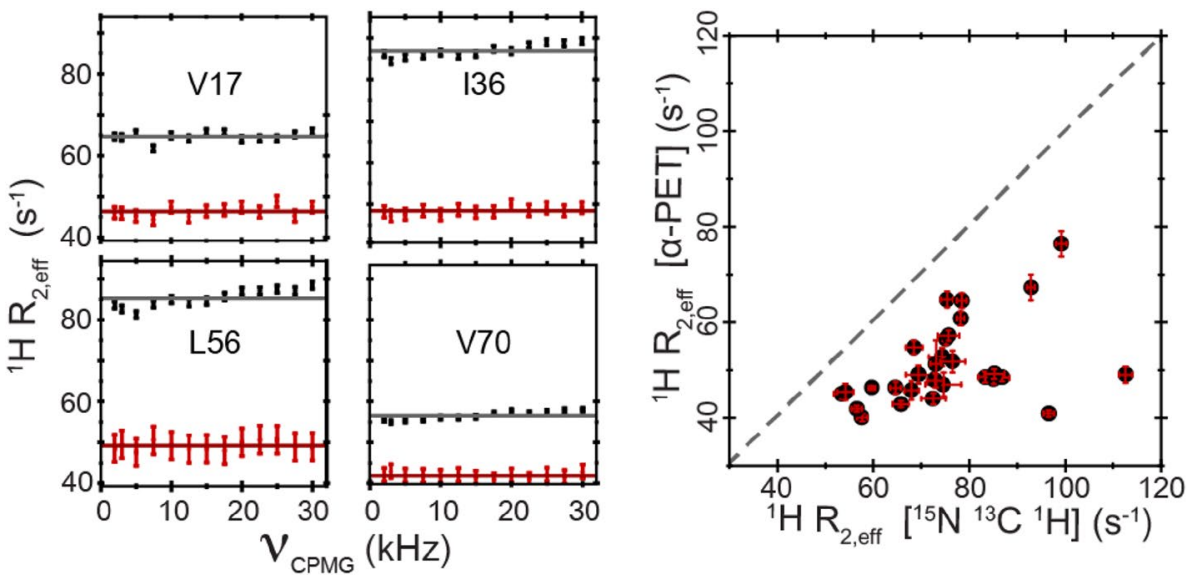

at $55 \mathrm{kHz}$. This shows that even for a highly homogeneous preparation of a membrane protein, $\alpha$-PET labeling efficiently reduces the proton dipolar broadening at $55 \mathrm{kHz}$.

The protection from solvent exchange observed for VDAC highlights an issue with perdeuteration for proteins that lack refolding protocols. Perdeuteration of membrane proteins (Medeiros-Silva et al. 2016; Ward et al. 2011) and large complexes (Andreas et al. 2016) in E. coli often results in deuterated amides that cannot be exchanged with protons from water. Such exchange protected regions of the protein become inaccessible in the perdeuteration and backexchange approach, limiting the analysis to solvent accessible regions (Andreas et al. 2015; Chevelkov et al. 2006; Fricke et al. 2017; Zhou et al. 2007a, b; Ward et al. 2015), although such limited exchange phenomena can also be used to obtain functional information (Ward et al. 2011; Böckmann and Guittet 1997; Agarwal et al. 2010). Using $\alpha$-PET labeling, we are now able to detect both exchangeable as well as non-exchangeable amide protons in highly deuterated samples as shown previously for amino acid based media (Löhr et al. 2003).

Due to the size of the protein, unambiguous assignment of important cross-strand contacts was not possible in a 3D $\mathrm{H}(\mathrm{H}) \mathrm{CH}$ spectrum of VDAC. We therefore applied the better resolved 3D $(\mathrm{H}) \mathrm{C}(\mathrm{HH}) \mathrm{CH}$ spectrum to measure crossstrand contacts (Fig. 6). VDAC assembles as a beta barrel, a topology that places cross-strand $\mathrm{H} \alpha$ pairs in close proximity $(\sim 2.3 \AA)$, and much closer than sequential $\mathrm{H} \alpha$ spins, which are separated by about $4.5 \AA$. $28 \mathrm{H} \alpha-\mathrm{H} \alpha$ contacts were detected from this spectrum, of which we show the cross strand contact between residue phenylalanine 99 and isoleucine 114, which was assigned based on the existing ${ }^{13} \mathrm{C}$ and ${ }^{15} \mathrm{~N}$ assignments of this protein (Eddy et al. 2015a, b) and (H)NCAHA and (H)N(CO)CAHA spectra. The current published assignments (32\% of 283 residues) of VDAC do not allow a characterization of all 28 peaks. However, resolving 28 peaks is significant, considering that only $\sim 4$ amide-amide or alpha-alpha contacts are available in each transmembrane beta sheet interface, of which VDAC has 19. Further analysis of the expected contacts in VDAC is show in in Fig. S10 This demonstrates a successful implementation of $\alpha$-PET labelling for structure determination in a challenging $32 \mathrm{kDa}$ membrane protein embedded in lipid bilayers, where structural restraints are particularly difficult to identify (Eddy et al. 2015).

\section{a-PET labeling for solution NMR}

The $\alpha$-PET labeling approach is also beneficial for the study of proteins in solution, when deuteration is needed to reduce transverse relaxation rates (LeMaster and Richards 1988; Torchia et al. 1988). Figure 7 and Tables S4-S5 show the reduction in $\mathrm{R}_{2}$ relaxation rates due to the high level of deuteration in $\alpha$-PET labeled Ubiquitin. Such improvement in relaxation rates is important for the study of protein dynamics. For example in detection of $\mathrm{H} \alpha$ relaxation dispersion, fractional deuteration was used to improve $\mathrm{R}_{2}$ (Lundström et al. 2009; Vallurupalli et al. 2009). The current labeling incorporates the alpha positions at $100 \%$ for most residues, with a high overall deuteration level, which improves sensitivity as compared with random fractional deuteration.

\section{Conclusions}

Here, we introduced a new method to label $\mathrm{H} \alpha$ protons in a protein without significant isotopic scrambling, and demonstrated how this new sensitive magnetic probe in the backbone of the protein adds new structural information even at below $60 \mathrm{kHz}$ MAS. The $\alpha$-PET labeling approach has several advantages, (i) adaptation of the cells to $\mathrm{D}_{2} \mathrm{O}$ is not required, (ii) it gives similar yields as deuterated expression in M9 media, and (iii) costs are similar to production of deuterated proteins. It is expected to be particularly useful for deuteration of proteins that lack refolding protocols, such as membrane proteins. 
In this demonstration, we used a commercially available crude snake venom extract to generate keto acids. This approach results in the designed incorporation of alpha protons for Tyr, Phe, Leu, Ile, Gly, Gln, Asn, Asp, Glu and Met. In the future, further optimization of the method might entail other LAAOs with different substrate specificity, perhaps in combination with auxotrophic strains to limit unwanted reaction pathways. In addition, other amino acid mixtures or expression systems could be investigated. This might allow labeling of lysine, arginine, and histidine, which were currently left deuterated.

\section{Supporting Information}

Quantification of labeling patterns, LAAO activity, measurement of relaxation times under $55 \mathrm{kHz}$ MAS, $\mathrm{H} \alpha \mathrm{R}_{2}$ in solution and spectral acquisition parameters.

Acknowledgements Open access funding provided by Max Planck Society. We thank Pablo Trigo Mourino for helping to set up solution NMR measurements and Christian Griesinger, Tobias Schubeis and Guido Pintacuda for useful discussions. We also thank Ashok Kumar Rout for NOE data in ubiquitin. We acknowledge financial support from the MPI for Biophysical Chemistry, and from the Deutsche Forschungsgemeinschaft (Emmy Noether program Grant AN1316/11, SFB803 Grant INST 186/794-3 Project A04).

OpenAccess This article is distributed under the terms of the Creative Commons Attribution 4.0 International License (http://creativeco mmons.org/licenses/by/4.0/), which permits unrestricted use, distribution, and reproduction in any medium, provided you give appropriate credit to the original author(s) and the source, provide a link to the Creative Commons license, and indicate if changes were made.

\section{References}

Agarwal V, Reif B (2008) Residual methyl protonation in perdeuterated proteins for multi-dimensional correlation experiments in MAS solid-state NMR spectroscopy. J Magn Reson 194:16-24

Agarwal V, Linser R, Fink U, Faelber K, Reif B (2010) Identification of hydroxyl protons, determination of their exchange dynamics, and characterization of hydrogen bonding in a microcrystallin protein. J Am Chem Soc 132:3187-3195

Akbey Ü, Lange S, Franks WT, Linser R, Rehbein K, Diehl A, Van Rossum BJ, Reif B, Oschkinat H (2010) Optimum levels of exchangeable protons in perdeuterated proteins for proton detection in MAS solid-state NMR spectroscopy. J Biomol NMR 46:67-73

Andreas LB, Le T, Jaudzems K, Pintacuda G (2015) High-resolution proton-detected NMR of proteins at very fast MAS. J Magn Reson 253:36-49

Andreas LB, Jaudzems K, Stanek J, Lalli D, Bertarello A, Le Marchand T, Cala-De Paepe D, Kotelovica S, Akopjana I, Knott B, Wegner S, Engelke F, Lesage A, Emsley L, Tars K, Herrmann T, Pintacuda G (2016) Structure of fully protonated proteins by protondetected magic-angle spinning NMR. Proc. Natl. Acad. Sci. 113, 9187-9192
Arbor A (1967) On the reaction mechanism acid oxidase * of Crotalus adamanteus. J Biol Chem 242:1259-1264

Asami S, Schmieder P, Reif B (2010) High resolution 1 H-detected solid-state NMR spectroscopy of protein aliphatic resonances: access to tertiary structure information. J Am Chem Soc 132:15133-15135

Asami S, Szekely K, Schanda P, Meier BH, Reif B (2012) Optimal degree of protonation for $1 \mathrm{H}$ detection of aliphatic sites in randomly deuterated proteins as a function of the MAS frequency. $\mathrm{J}$ Biomol NMR 54:155-168

Bardaweel SK (2014) D-amino acids: prospects for new therapeutic agents. J Med Bioeng 3:195-198

Bax A, Davis DG (1985) MLEV-17-based two-dimensional homonuclear magnetization transfer spectroscopy. J Magn Reson 65:355-360

Böckmann A, Guittet E (1997) Determination of fast proton exchange rates of biomolecules by NMR using water selective diffusion experiments. FEBS Lett 418:127-130

Brown SP (2012) Applications of high-resolution 1H solid-state NMR. Solid State Nucl Magn Reson 41:1-27

Cala-De Paepe D, Stanek J, Jaudzems K, Tars K, Andreas LB, Pintacuda G (2017) Is protein deuteration beneficial for proton detected solid-state NMR at and above $100 \mathrm{kHz}$ magic-angle spinning? Solid State Nucl Magn Reson 87:126-136

Chevelkov V, Rehbein K, Diehl A, Reif B (2006) Ultrahigh resolution in proton solid-state NMR spectroscopy at high levels of deuteration. Angew Chem Int Ed 45:3878-3881

Chevelkov V, Faelber K, Schrey A, Rehbein K, Diehl A, Reif B (2007) Differential line broadening in MAS solid-state NMR due to dynamic interference. J Am Chem Soc 129:10195-10200

Crotalus I, Allen R (2013) Crystalline of Crotalus udamanteus. Public Health 235:2013-2018

Dolder M, Zeth K, Tittmann P, Gross H, Welte W, Wallimann T (1999) Crystallization of the human, mitochondrial voltagedependent anion-selective channel in the presence of phospholipids. J Struct Biol 127:64-71

Dunathan HC, Davis L, Kury PG, Kaplan M (1968) The stereochemistry of enzymatic transamination. Biochemistry 7:4532-4537

Eddy MT, Ong TC, Clark L, Teijido O, Van Der Wel PCA, Garces R, Wagner G, Rostovtseva TK, Griffin RG (2012) Lipid dynamics and protein-lipid interactions in $2 \mathrm{D}$ crystals formed with the $\beta$-barrel integral membrane protein VDAC1. J Am Chem Soc 134:6375-6387

Eddy MT, Su Y, Silvers R, Andreas L, Clark L, Wagner G, Pintacuda G, Emsley L, Griffin RG (2015a) Lipid bilayer-bound conformation of an integral membrane beta barrel protein by multidimensional MAS NMR. J Biomol NMR 61:299-310

Eddy MT, Andreas L, Teijido O, Su Y, Clark L, Noskov SY, Wagner G, Rostovtseva TK, Griffin RG (2015b) Magic angle spinning nuclear magnetic resonance characterization of voltage-dependent anion channel gating in two-dimensional lipid crystalline bilayers. Biochemistry 54:994-1005

Fiaux J, Bertelsen EB, Horwich AL, Wüthrich K Uniform and residue-speci c $15 \mathrm{~N}$-labeling of proteins on a highly deuterated background. J. Biomol. NMR 289-297 (2004)

Fricke P, Chevelkov V, Zinke M, Giller K, Becker S, Lange A (2017) Backbone assignment of perdeuterated proteins by solid-state NMR using proton detection and ultrafast magic-Angle spinning. Nat Protoc 12:764-782

Hishinuma F, Izaki K, Takahashi H (1969) Effects of glycine and d-amino acids on growth of various microorganisms. Agric Biol Chem 33:1577-1586

Hossain GS, Li J, Shin HD, Du G, Liu L, Chen J (2014) L-amino acid oxidases from microbial sources: Types, properties, functions, and applications. Appl Microbiol Biotechnol 98:1507-1515 
Isaacson RL, Simpson PJ, Liu M, Cota E, Zhang X, Freemont P, Matthews S (2007) A new labeling method for methyl transverse relaxation-optimized spectroscopy NMR spectra of alanine residues. J Am Chem Soc 129:15428-15429

Jain MG, Lalli D, Stanek J, Gowda C, Prakash S, Schwarzer TS, Schubeis T, Castiglione K, Andreas LB, Madhu PK, Pintacuda G, Agarwal V (2017) Selective ${ }^{1} \mathrm{H}-{ }^{1} \mathrm{H}$ distance restraints in fully protonated proteins by very fast magic-angle spinning solid-state NMR. J Phys Chem Lett 8:2399-2405

Kainosho M, Torizawa T, Iwashita Y, Terauchi T, Mei Ono A, Güntert P (2006) Optimal isotope labelling for NMR protein structure determinations. Nature 440:52-57

Kim SH, Schneider BL, Reitzer L (2010) Genetics and regulation of the major enzymes of alanine synthesis in Escherichia coli. J Bacteriol 192:5304-5311

Lazar G, Desjarlais JR, Handel TM (1997) De novo design of the hydrophobic core of ubiquitin. Protein Sci 6:1167-1178

Lemaster DM (1990) Deuterium labeling in NMR structural-analysis of larger proteins. Q Rev Biophys 23:133-174

LeMaster DM, Richards FM (1988) NMR sequential assignment of Escherichia coli thioredoxin utilizing random fractional deuteriationt. Biochemistry 27:142-150

Lewandowski JR, Dumez JN, Akbey Ü, Lange S, Emsley L, Oschkinat $H$ (2011) Enhanced resolution and coherence lifetimes in the solid-state NMR spectroscopy of perdeuterated proteins under ultrafast magic-angle spinning. J Phys Chem Lett 2:2205-2211

Löhr F, Katsemi V, Hartleib J, Günther U, Rüterjans H (2003) A strategy to obtain backbone resonance assignments of deuterated proteins in the presence of incomplete amide $2 \mathrm{H} / 1 \mathrm{H}$ back-exhange. $\mathrm{J}$ Biomol NMR 25:291-311

Loscha KV, Otting G (2013) Biosynthetically directed2H labelling for stereospecific resonance assignments of glycine methylene groups. J Biomol NMR 55:97-104

Lundström P, Hansen DF, Vallurupalli P, Kay LE (2009) Accurate measurement of alpha proton chemical shifts of excited protein states by relaxation dispersion NMR spectroscopy. J Am Chem Soc 131:1915-1926

Medeiros-Silva J, Mance D, Daniëls M, Jekhmane S, Houben K, Baldus M, Weingarth M (2016) 1H-detected solid-state NMR studies of water-inaccessible proteins in vitro and in situ. Angew Chem Int Ed 55:13606-13610

Rudman D, Meister A (1953) Transamination in Escherichia coli. J Biol Chem 200:591-604

Nuutinen JT, Marttinen E, Soliymani R, Hilden K, Timonen AS (2012) L-amino acid oxidase of the fungus Hebeloma cylindrosporum displays substrate preference towards glutamate. Microbiology 158:272-283

O'Brien ES, Lin DW, Fuglestad B, Stetz MA, Gosse T, Tommos C, Wand AJ (2018) Improving yields of deuterated, methyl labeled protein by growing in $\mathrm{H} 2 \mathrm{O}$. J Biomol NMR 0:0

Pauli J, Van Rossum B, Förster H, De Groot HJM, Oschkinat H (2000) Sample optimization and identification of signal patterns of amino acid side chains in 2D RFDR spectra of the $\alpha$-Spectrin SH3 domain. J Magn Reson 143:411-416

Schneider R, Etzkorn M, Giller K, Daebel V, Eisfeld J, Zweckstetter M, Griesinger C, Becker S, Lange A (2010) The native conformation of the human VDAC1 N terminus. Angew Chem Int Ed 49:1882-1885

Stanek J, Andreas LB, Jaudzems K, Cala D, Lalli D, Bertarello A, Schubeis T, Akopjana I, Kotelovica S, Tars K, Pica A (2016) NMR Spectroscopic Assignment of Backbone and Side-Chain Protons in Fully Protonated Proteins: Microcrystals, Sedimented Assemblies, and Amyloid Fibrils. Angew Chem Int Ed 55(50):15504-15509. https://doi.org/10.1002/anie.201607084
Sun MZ, Guo C, Tian Y, Chen D, Greenaway FT, Liu S (2010) Biochemical, functional and structural characterization of AkbuLAAO: A novel snake venom 1-amino acid oxidase from Agkistrodon blomhoffii ussurensis. Biochimie 92:343-349

Torchia DA, Sparks SW, Bax A (1988) Delineation of $\alpha$-helical domains in deuteriated staphylococcal nuclease by 2D NOE NMR spectroscopy. J Am Chem Soc 110:2320-2321

Tugarinov V, Kay LE, Ile (2003) Leu, and Val methyl assignments of the 723-residue malate synthase $\mathrm{G}$ using a new labeling strategy and novel NMR methods. J Am Chem Soc 125:13868-13878

Vallurupalli P, Hansen DF, Lundström P, Kay LE (2009) CPMG relaxation dispersion NMR experiments measuring glycine $1 \mathrm{H} \alpha$ and $13 \mathrm{C} \alpha$ chemical shifts in the 'invisible' excited states of proteins. J Biomol NMR 45:45-55

Velyvis A, Ruschak AM, Kay LE (2012) An economical method for production of $2 \mathrm{H}, 13 \mathrm{CH} 3$-threonine for solution NMR studies of large protein complexes: application to the $670 \mathrm{kDa}$ proteasome. PLOS ONE 7:1-8

Wang S, Ladizhansky V (2014) Recent advances in magic angle spinning solid state NMR of membrane proteins. Prog Nucl Magn Reson Spectrosc 82:1-26

Ward ME, Shi L, Lake E, Krishnamurthy S, Hutchins H, Brown LS, Ladizhansky V (2011) Proton-detected solid-state NMR reveals intramembrane polar networks in a seven-helical transmembrane protein proteorhodopsin. J Am Chem Soc 133:17434-17443

Ward ME, Ritz E, Ahmed MAM, Bamm VV, Harauz G, Brown LS, Ladizhansky V (2015) Proton detection for signal enhancement in solid-state NMR experiments on mobile species in membrane proteins. J Biomol NMR. https://doi.org/10.1007/s10858-015-9997-5

Wellner D (1970) Stereospecificity of enzymatic formation and oxidation of glycine. Biochemistry 9:2307-2310

Xue K, Sarkar R, Motz C, Asami S, Camargo DCR, Decker V, Wegner S, Tosner Z, Reif B Limits of resolution and sensitivity of proton Detected MAS solid-state NMR experiments at $111 \mathrm{kHz}$ in deuterated and protonated proteins. Sci Rep 7, (2017)

Yamazaki T, Tochio H, Furui J, Aimoto S, Kyogoku Y (1997) Assignment of backbone resonances for larger proteins using the $13 \mathrm{C}-1 \mathrm{H}$ coherence of a $1 \mathrm{H}(\alpha)-, 2 \mathrm{H}-, 13 \mathrm{C}-$, and $15 \mathrm{~N}$-labeled sample. J Am Chem Soc 119:872-880

Yoshimura T, Jhee K-H, Soda K (1996) Stereospecificity for the Hydrogen transfer and molecular evolution of pyridoxal enzymes. Biosci Biotechnol Biochem 60:181-187

Zhang R, Nishiyama Y, Ramamoorthy A (2015) Proton-detected 3D $1 \mathrm{H} / 13 \mathrm{C} / 1 \mathrm{H}$ correlation experiment for structural analysis in rigid solids under ultrafast-MAS above $60 \mathrm{kHz}$. J Chem Phys 143:164201

Zhou P, Sun LJ, Dötsch V, Wagner G, Verdine GL (1998) Solution structure of the core NFATC1/DNA complex. Cell 92:687-696

Zhou DH, Shah G, Cormos M, Mullen C, Sandoz D, Rienstra CM (2007a) Proton-detected solid-state NMR spectroscopy of fully protonated proteins at $40 \mathrm{kHz}$ magic-angle spinning. J Am Chem Soc 129:11791-11801

Zhou DH, Shea JJ, Nieuwkoop AJ, Franks WT, Wylie BJ, Mullen C, Sandoz D, Rienstra CM (2007b) Solid-state protein-structure determination with proton-detected triple-resonance $3 \mathrm{D}$ magic-angle-spinning NMR spectroscopy. Angew Chem Int Ed 46:8380-8383

Publisher's Note Springer Nature remains neutral with regard to jurisdictional claims in published maps and institutional affiliations. 